Research Article

\title{
Study on Long-Term Dynamic Mechanical Properties and Degradation Law of Sandstone under Freeze-Thaw Cycle
}

\author{
Qingsong Pu, ${ }^{1,2}$ Junhong Huang $\mathbb{D}^{1,3,4}$ Fuling Zeng, ${ }^{1,2}$ Yi Luo ${ }^{1 D},{ }^{1}$ Xinping Li, ${ }^{1}$ Jixue Zhou, ${ }^{1,2}$ \\ and Shilong Zheng ${ }^{1,2}$ \\ ${ }^{1}$ Hubei Key Laboratory of Roadway Bridge and Structure, Wuhan University of Technology, Wuhan, China \\ ${ }^{2}$ School of Civil Engineering and Architecture, Wuhan University of Technology, Wuhan, China \\ ${ }^{3}$ School of Safety Science and Emergency Management, Wuhan University of Technology, Wuhan, China \\ ${ }^{4}$ School of Resource, Environmental Science and Engineering, Hubei University of Science and Technology, Xianning, China
}

Correspondence should be addressed to Junhong Huang; junhonghuang@whut.edu.cn

Received 4 May 2020; Revised 22 June 2020; Accepted 1 July 2020; Published 16 July 2020

Academic Editor: Seyed Mahdi Seyed Kolbadi

Copyright ( 92020 Qingsong Pu et al. This is an open access article distributed under the Creative Commons Attribution License, which permits unrestricted use, distribution, and reproduction in any medium, provided the original work is properly cited.

This study is based on the tunnel-face slope engineering of Dongfeng tunnel in Shanxi section of China's Shuozhou-Huanghua Railway. The sandstone specimens in the perennial freeze-thaw zone of the slope were collected to carry out freeze-thaw cycle static physical mechanics test and split Hopkinson pressure bar (SHPB) dynamic mechanical test. Thus, the damage process of sandstone under freeze-thaw cycle and impact load is studied. Also, the dynamic compressive strength and dynamic elastic modulus of sandstone are analysed under different loading strain rates and freeze-thaw cycle based on LS-DYNA, a dynamic finite element program. The results showed that the dynamic compressive strength of sandstone subjected to multiple freeze-thaw cycles under $0.04 \mathrm{MPa}$ air pressure has a greater damage ratio than that under $0.055 \mathrm{MPa}$ and $0.07 \mathrm{MPa}$ air pressure, which was more likely to cause damage to slope sandstone than in actual engineering; the dynamic compressive strength and elastic modulus of sandstone decrease greatly within a certain range of freeze-thaw cycles and loading strain rate, leading to significant deterioration. When the freeze-thaw cycle exceeded 200 times and the strain rate was greater than $200 \mathrm{~s}^{-1}$, the physical and mechanical properties of sandstone gradually tended to be stable.

\section{Introduction}

During the construction of mining, roads, and tunnels, in cold regions, the construction zone is often subjected to blasting vibration, heavy truck transportation vibration, earthquake vibration, and other dynamic loads. The frost heaving effect of the pore water inside the rock with the temperature change promotes the development of pores, and when the pores are subjected to dynamic loading, there is a serious impact on the stability of the rock engineering. It is of great significance for the stability and life cycle prediction of rock engineering in cold regions to analyse the deterioration law of static and dynamic mechanical parameters, strain rate effect, and rock failure mode of fractured rock masses under the coupling of freeze-thaw cycles and dynamic loads [1].
Domestic and international scholars have conducted indepth research on the static and dynamic mechanical properties of rocks under the action of freeze-thaw cycles [2, 3]. Many scholars have studied the variation law of the longitudinal wave velocity, strength, elastic modulus, and permeability of different rocks under the action of freeze-thaw cycles $[4,5]$. In 2013, a serious landslide accident occurred in the Lhasa Jiama mining area in China, causing serious casualties and property losses. The main cause of the accident was the deterioration of the mechanical properties of the rock mass caused by freeze-thaw cycles and dynamic loads [6]. Therefore, it is of great significance to study the dynamic mechanical properties of rocks under the action of freeze-thaw cycles and dynamic disturbance for construction in cold regions.

The freeze-thaw cycle induces the fracture propagation in rock mass and then weakens the mechanical parameters 
such as elastic modulus and uniaxial compressive strength of rock mass. Deng et al. [7] made a back analysis of the rock mass mechanical parameters in the underground project through Seepage-Stress Coupled Analysis. Xu et al. [8] and Deng et al. [9] studied the energy distribution and transmission process in dynamic compression tests and dynamic tensile tests for different rock types and analysed the variation law of the dynamic energy parameters, absorption energy, reflection energy, projection energy, and other related energy. Zhang et al. [10], Alam et al. [11], and Yavuz [12] studied the deterioration law of sandstone under freeze-thaw action and quasistatic and dynamic loading conditions and analysed it from the change in the mechanical parameters such as the porosity, $\mathrm{P}$-wave velocity, strength, and elastic modulus. Wang et al. [13] through improved the sandstone rheological constitutive model and optimized the algorithm of parameter inversion and put forward a long-term stability analysis model that can accurately reflect the rheological characteristics of surrounding rocks under the complex geological condition including high stress induced by great depth and high seepage pressure. Mutlutürk et al. [14] and Wang et al. [15] proposed a mathematical model for describing the integrity loss of rocks under freeze-thaw cycles. The reliability of the model was verified by studying ten different types of rocks. Zhang et al. [16] and He and Cui [17] would be simulating the failure process of rock under dynamic loading by a numerical simulation method and analysing the crack propagation path of rock after the reliability of the model was verified by the SHPB tests.

In this paper, the typical sandstone sample of Dongfeng tunnel slope of Shuohuang railway in China is taken as the research object. Through the laboratory freeze-thaw cycle test, SHPB impact compression test, and dynamic finite element numerical simulation test, the degradation law of dynamic mechanical properties of sandstone is studied and the numerical relationship between mechanical parameters such as dynamic strength and the number of freeze-thaw cycles and strain rate is established. It provides theoretical basis for the study of long-term stability and protection engineering of rock mass in the dynamic disturbance environment in cold region. The specific flowchart of research methodology is shown in Figure 1.

\section{Dynamic Mechanical Test of Freeze-Thaw Rock Mass in Dongfeng Tunnel-Face Slope}

2.1. Engineering Background of Freeze-Thaw Rock Mass in Dongfeng Tunnel-Face Slope. Dongfeng tunnel is located in the northwest of Shuozhou-Huanghua Railway Shanxi section [18], with a total length of 3,290 meters and an altitude of about 1,200 meters as an area of high latitudes, the highest temperature of 20 degrees Celsius in winter, and the lowest temperature of minus 20 degrees Celsius. It is affected by the freeze and thaw obviously. Besides, Dongfeng tunnel is the hub of the heavy-haul railway such as coal transportation. Due to the heavy tonnage and heavy acting load of transport trains, the rock slope involved in the tunnel has been under unfavorable conditions such as heavy train load

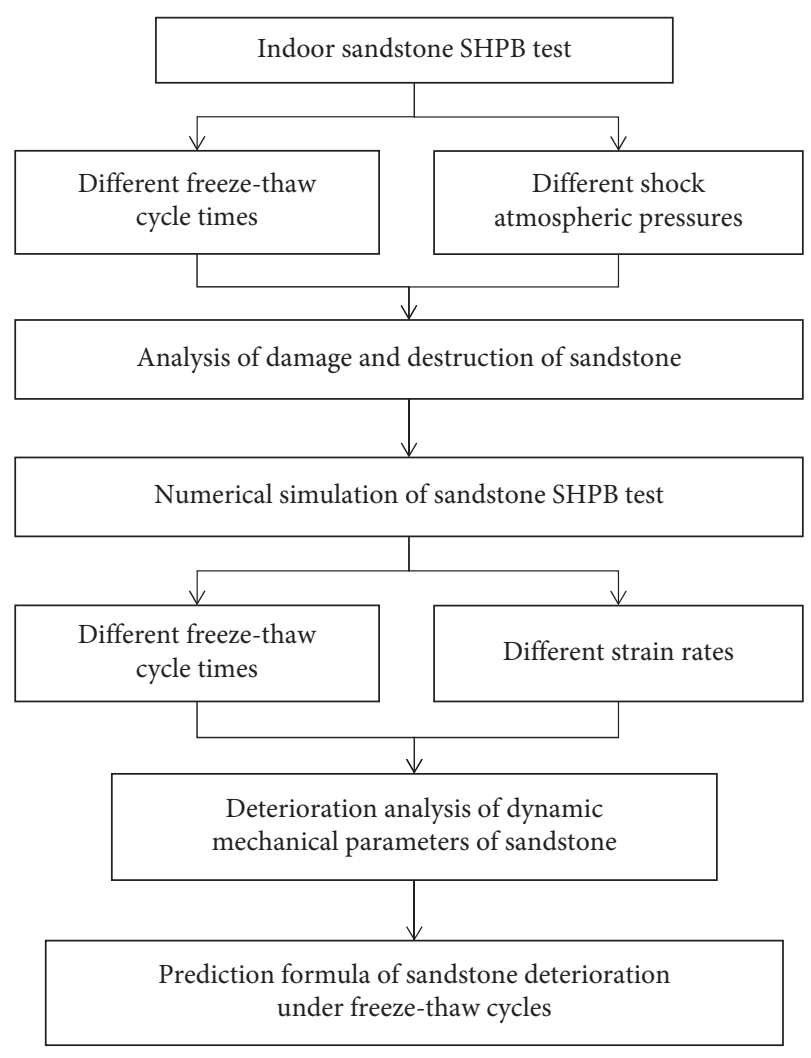

FIgURE 1: Specific flowchart of research methodology.

and freeze-thaw cycle for a long time, so more attention should be paid to its self-stability ability.

2.2. Test Equipment and Principles. The SHPB device used in the test is shown in Figure 2. The main equipment includes launcher, bullet, buffer rod, bar, adjusting bracket, and control console; the loading system includes air compressor, transmission pipeline, and control valve; the test recording system includes elastic velocity and dynamic strain measuring system, in which the length of the incident rod is $4 \mathrm{~m}$, the transmission rod is $3 \mathrm{~m}$, and the pressure rod diameter is $100 \mathrm{~mm}$. Due to the difference in wave impedance between the rod and the specimen, part of the incident wave is reflected for the incident rod to form a reflected wave, while the other part enters the transmission rod through the specimen to form a transmitted wave (see Figure 3 ). The voltage data measured by the strain gauge sensor on the incident bar and the transmission bar are converted into the data of stress, strain, and strain rate with calculation principle in the following equations, respectively [1]:

$$
\begin{aligned}
\sigma & =\frac{A_{0} E_{0}}{2 A_{1}}\left(\varepsilon_{I}+\varepsilon_{R}+\varepsilon_{T}\right), \\
\varepsilon & =\frac{C_{0}}{L_{1}} \int_{0}^{t}\left(\varepsilon_{I}-\varepsilon_{R}-\varepsilon_{T}\right) \mathrm{d} t, \\
\dot{\varepsilon} & =\frac{C_{0}}{L_{1}}\left(\varepsilon_{I}-\varepsilon_{R}-\varepsilon_{T}\right),
\end{aligned}
$$




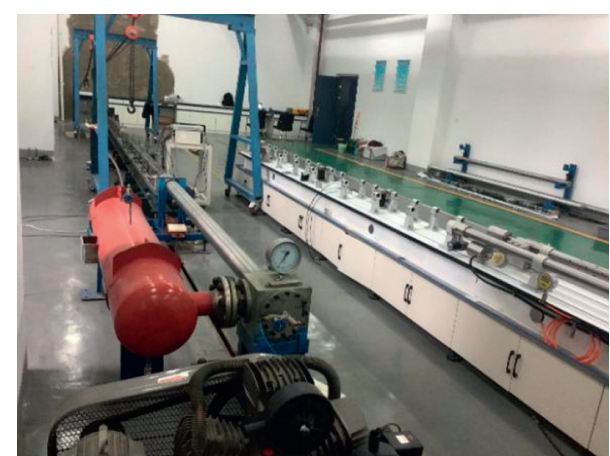

FIgURE 2: Laboratory SHPB test equipment.

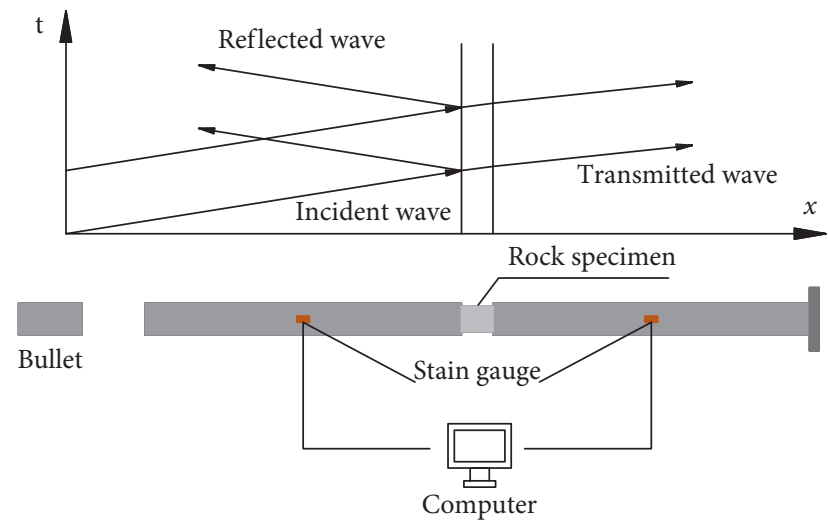

FIGURE 3: SHPB impact compression test loading process diagram.

where $E_{0}, A_{0}$, and $C_{0}$ refer to the elastic modulus, crosssectional area, and compressional wave velocity of the pressure bar, respectively, $C_{0}=\sqrt{E_{0} / \rho_{0}} ; \varepsilon_{I}, \varepsilon_{R}$, and $\varepsilon_{T}$ refer to incident strain, reflected strain, and transmitted strain, respectively; $\varepsilon$ refers to stain and $\dot{\varepsilon}$ refers to stain rate; $A_{1}, L_{1}$ refer to the cross-sectional area and length of the specimen, respectively.

2.3. SHPB Test Protocol. The sandstone in the test came from the tunnel-face slope of Dongfeng Tunnel of ShuozhouHuanghua Railway; all sandstone samples in the freezingthawing cycle tests were in the state of saturated water. According to the International Society for Rock Mechanics rock mechanics test standard, the sandstone specimen is processed into $\Phi 50 \mathrm{~mm} \times 100 \mathrm{~mm}$ cylinders, with flatness, parallelism, and perpendicularity to the test specimens code requirements. The specimens were tested by ultrasonic waves, and the one with similar ultrasonic wave velocity was selected to ensure the uniformity inside.

The rock cutting machine and end face grinding machine and other equipment are used to process freeze-thaw sandstone specimens to produce sandstone specimens with a size of $\varnothing 50 \mathrm{~mm} \times 23 \mathrm{~mm}$. According to the indoor preimpact test, when the impact pressure is below $0.04 \mathrm{MPa}$, the bullet will not pop well enough, while when the impact pressure is above $0.07 \mathrm{MPa}$, the sandstone specimen will be too crushed, which is not conducive to observing the failure form of the rock under impact load. In this paper, three groups of impact compression tests were designed, with an impact pressure of $0.04 \mathrm{MPa}, 0.055 \mathrm{MPa}$, and $0.07 \mathrm{MPa}$, respectively. To ensure the accuracy of the tests, each group of tests was carried out three times.

2.4. Analysis of Test Results. In this paper, a comparative analysis is conducted on the sandstone that has undergone 0 , $20,40,80$, and 120 freeze-thaw cycles $[19,20]$, through which the typical physical and mechanical parameters of the sandstone specimens under the freeze-thaw cycle were obtained (Table 1).

The dynamic stress-strain curves of sandstone specimens with different freeze-thaw cycles under three impact pressures are shown in Figures 4-6. To sum up the dynamic compressive strength in the curve, namely, the stress-strain peak, which is shown in Table 2, it was indicated that when the impact pressure increases from $0.04 \mathrm{MPa}$ to $0.055 \mathrm{MPa}$ and from $0.055 \mathrm{MPa}$ to $0.07 \mathrm{MPa}$ in the same times of freezethaw, the dynamic compressive strength of sandstone increased by about two times. However, by comparing the damage values of sandstone specimens under different impact air pressure, it can be found that the dynamic compressive strength of sandstone under $0.04 \mathrm{MPa}$ air pressure suffered from the highest damage rate after being affected by freeze-thaw cycle, and such strength suffered from the lowest damage rate under $0.07 \mathrm{MPa}$ air pressure. This indicated that the smaller was the strain rate of sandstone and the greater was the influence of the mechanical properties produced by the freeze-thaw cycle. Compared with the SHPB impact test in the laboratory, the strain rate was smaller in the heavy-haul train, so it could be inferred that the dynamic mechanical properties of sandstone under the action of the heavy load train were more affected by the freeze-thaw cycle, which should be paid enough attention to.

\section{Study on Mechanical Parameter Degradation of Freeze-Thaw Rock Mass in Dongfeng Tunnel- Face Slope}

3.1. Study on Degradation of Static Mechanical Parameters of Sandstone with Different Freeze-Thaw Cycles. The design service life of the tunnel is hundred years. Assuming the rock experiences about three freeze-thaw cycles in a year, the dynamic mechanical properties of the rock after about 300 freeze-thaw cycles need to be considered. Through fitting the mechanical parameters of measured sandstone specimens, as shown in Figure 7, uniaxial compressive strength and elastic modulus fitting formulas of sandstone specimens under different freeze-thaw cycles are obtained. Furthermore, the physical and mechanical parameters of sandstone under 150, 200, 250, and 300 freeze-thaw cycles are calculated [21]. A lot of test data show that the density and Poisson's ratio of sandstone specimens are not affected by the freeze-thaw cycle. Therefore, the physical and mechanical parameters of sandstone specimens under the action of high-order freeze-thaw cycles are shown in Table 3. 
TABle 1: Physical and static parameters of sandstone under freeze-thaw cycle.

\begin{tabular}{lcccc}
\hline Number of freeze-thaw cycles & Density $\left(\mathrm{kg} / \mathrm{m}^{3}\right)$ & Elastic modulus $(\mathrm{GPa})$ & Uniaxial compressive strength $(\mathrm{MPa})$ & Poisson's ratio \\
\hline 0 & 2688 & 24.11 & 42.32 & 0.2537 \\
20 & 2643 & 22.78 & 38.62 & 30.98 \\
40 & 2600 & 20.21 & 25.16 & 0.2635 \\
80 & 2586 & 14.36 & 2672 \\
120 & 2572 & 11.02 & 20.35 & 0.2715 \\
\hline
\end{tabular}

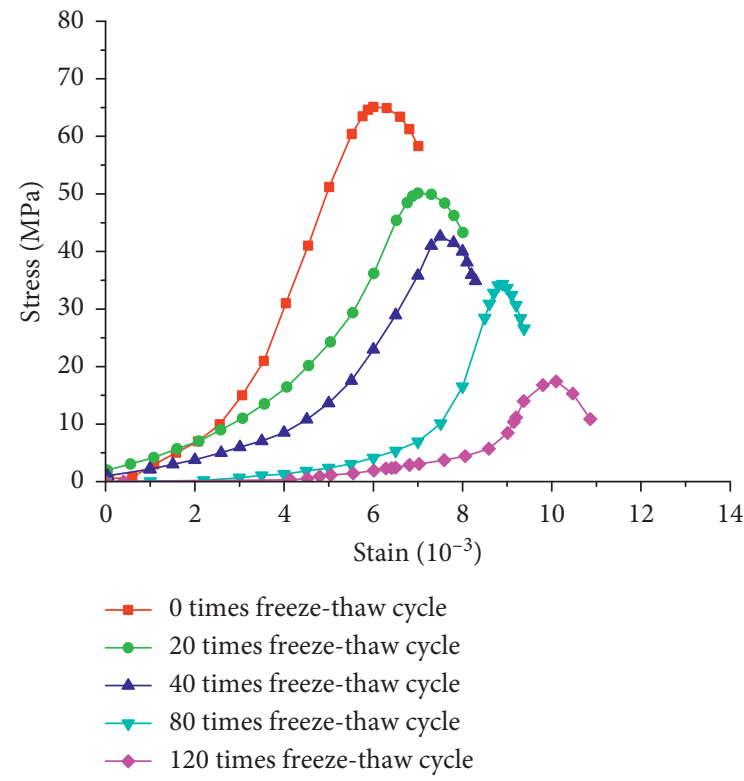

FIGURE 4: Stress-strain curves of sandstone in different freeze-thaw cycles under $0.04 \mathrm{MPa}$ impact pressure.

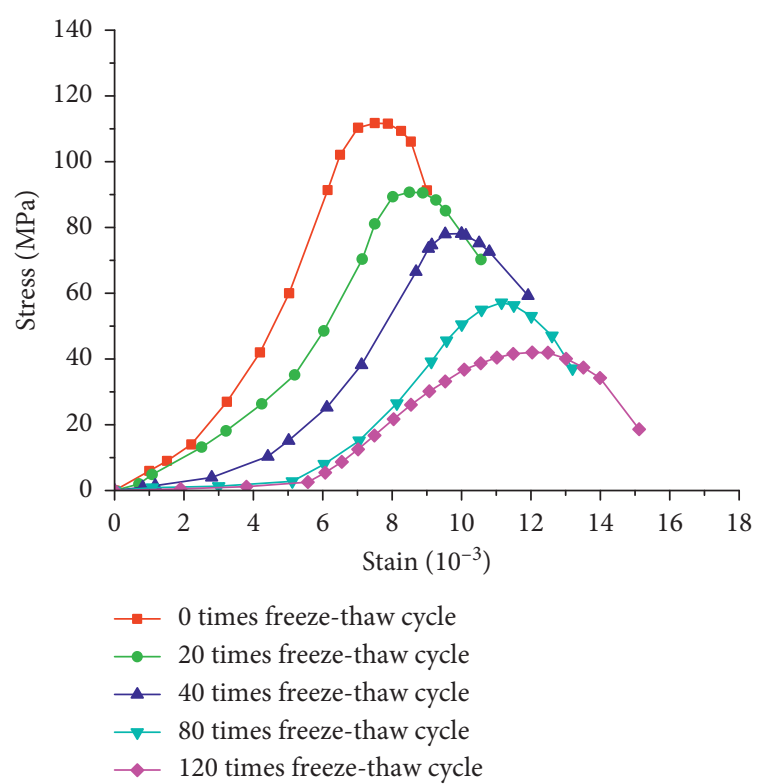

FiguRE 5: Stress-strain curves of sandstone in different freeze-thaw cycles under $0.055 \mathrm{MPa}$ impact pressure.

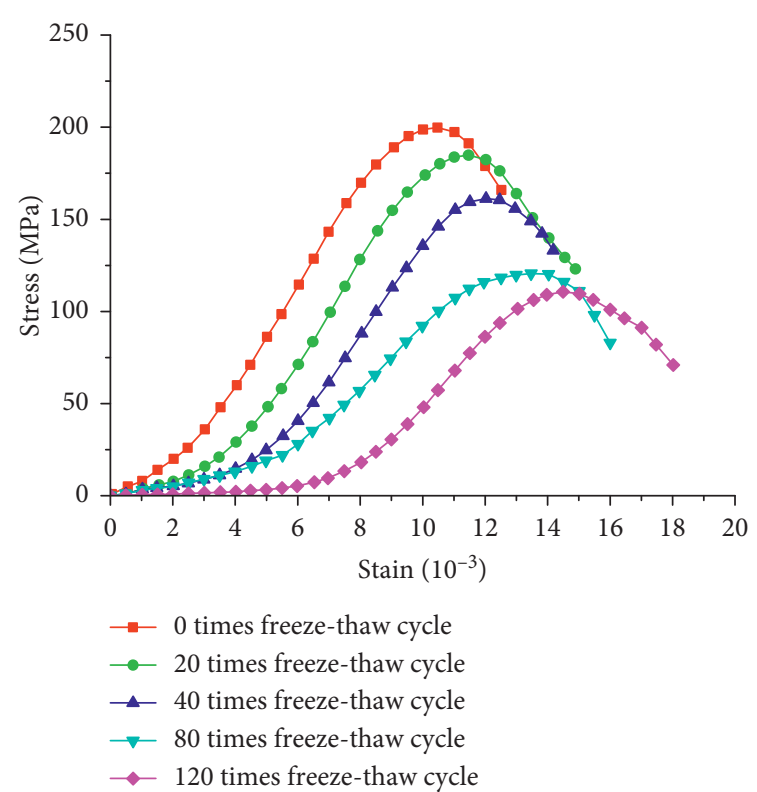

Figure 6: Stress-strain curve of sandstone with different freezethaw cycles under the impact pressure of $0.07 \mathrm{MPa}$.

3.2. Establishment of SHPB Numerical Simulation Test Model. In the numerical simulation test, a half sinusoidal stress wave was applied directly at the end of the incident bar to simulate the impulse process of approximate half sinusoidal stress pulse produced by the bullet hitting the incident bar. Different strain rate loading was realized by changing the peak value of the impact loads.

In this paper, the dynamic finite element program LSDYNA was applied to supplement the interior SHPB experiment analysis, which focused on nonlinear dynamic analysis with static analysis capabilities. Among them, the HJC constitutive model described the damage of rock brittle materials, such as concrete body, using the accumulation of the equivalent plastic strain and the plastic bulk strain, which was capable of dealing with high speed and large deformation. The numerical model used the Solid164 element to simulate the pressure bar and specimen. This is an eight-node hexahedral element, which has the degrees of freedom of translation, velocity, and acceleration in $X, Y$, and $Z$ directions.

The model length of the bar is $2 \mathrm{~m}$, the thickness of the specimen is $0.023 \mathrm{~m}$, and the radius is $0.05 \mathrm{~m}$. The incident bar and the transmission bar are evenly divided into 200 parts along the axial direction, and the specimen is evenly divided into 50 parts as shown in Figure 8. 
TABLE 2: Stress peaks of sandstone specimens under different impact pressures.

\begin{tabular}{lccccc}
\hline \multirow{2}{*}{ Impact pressure (MPa) } & \multicolumn{4}{c}{ Number of freeze-thaw cycles } \\
& 0 & 20 & 40 & 80 & 120 \\
\hline 0.04 & 65 & 50 & 42 & 34 & 17 \\
0.055 & 112 & 91 & 78 & 57 & 42 \\
0.07 & 200 & 185 & 161 & 121 & 111 \\
\hline
\end{tabular}

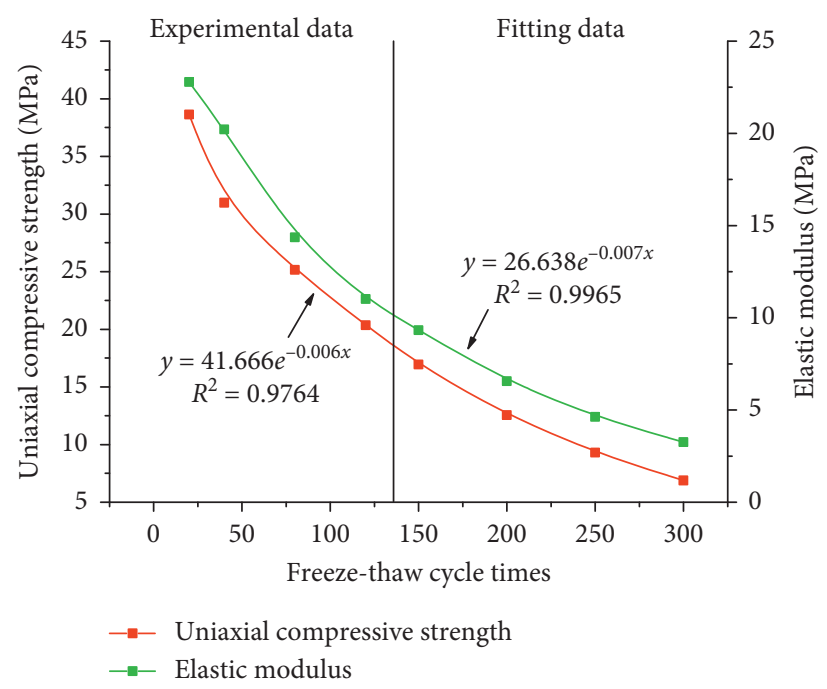

Figure 7: Fitting formulas for static compressive strength and elastic modulus of sandstone with different freeze-thaw cycles.

TABLE 3: Fitting values of physical and static parameters of sandstone under multiple freeze-thaw cycles.

\begin{tabular}{lcccc}
\hline Number of freeze-thaw cycles & Density $\left(\mathrm{kg} / \mathrm{m}^{3}\right)$ & Elastic modulus $(\mathrm{GPa})$ & Uniaxial compressive strength $(\mathrm{MPa})$ & Poisson's ratio \\
\hline 150 & 2572 & 7.91 & 14.93 & 0.2756 \\
200 & 2572 & 5.97 & 11.74 & 0.2756 \\
250 & 2572 & 4.51 & 9.23 & 0.2756 \\
300 & 2572 & 3.40 & 7.26 & 0.2756 \\
\hline
\end{tabular}

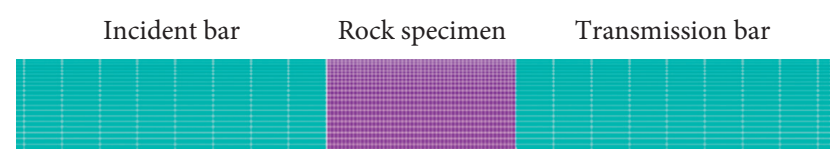

FIGURE 8: Establishment of the numerical simulation SHPB model.

The SHPB is made of steel, and the material parameters used in the numerical simulation are actual physical parameters, namely, density $\rho=7900 \mathrm{~kg} / \mathrm{m}^{3}$, elastic modulus $E=210 \mathrm{GPa}$, and Poisson's ratio $v=0.2$. The widely used $\mathrm{HJC}$ empirical constitutive model is selected as the material for the sandstone specimen.

\subsection{Study on Degradation of Dynamic Mechanical Parameters of Sandstone with Different Freeze-Thaw Cycles}

3.3.1. Load Selection in Numerical Simulation of SHPB. In this paper, the indoor SHPB test under the impact pressure of $0.07 \mathrm{MPa}$ is selected as the representative, and LS-DYNA is used to conduct numerical simulation tests. The measured load curve at the strain gauge position on the incident bar is shown in Figure 9, which is approximate to the semisinusoidal wave. In the numerical simulation, the semisinusoidal wave with similar amplitude and frequency is selected as the input load in the LS-DYNA numerical simulation test.

3.3.2. Feasibility Verification of Numerical Simulation Calculation of SHPB. Simulation of impact compression is carried out by LS-DYNA for four model specimens with different freeze-thaw cycles, and the dynamic compressive strength is shown in Figure 10, which is well consistent with the strength measured in the laboratory tests. Meanwhile, the failure morphology of model specimens is similar to that of sandstone in the impact compression test, both of which are split failure modes as shown in Figure 11. Since the numerical simulation results are similar to the laboratory test results in strength characteristics and failure modes, the numerical model could be used to simulate and analyse the impact test results of sandstone under different freeze-thaw cycles. 


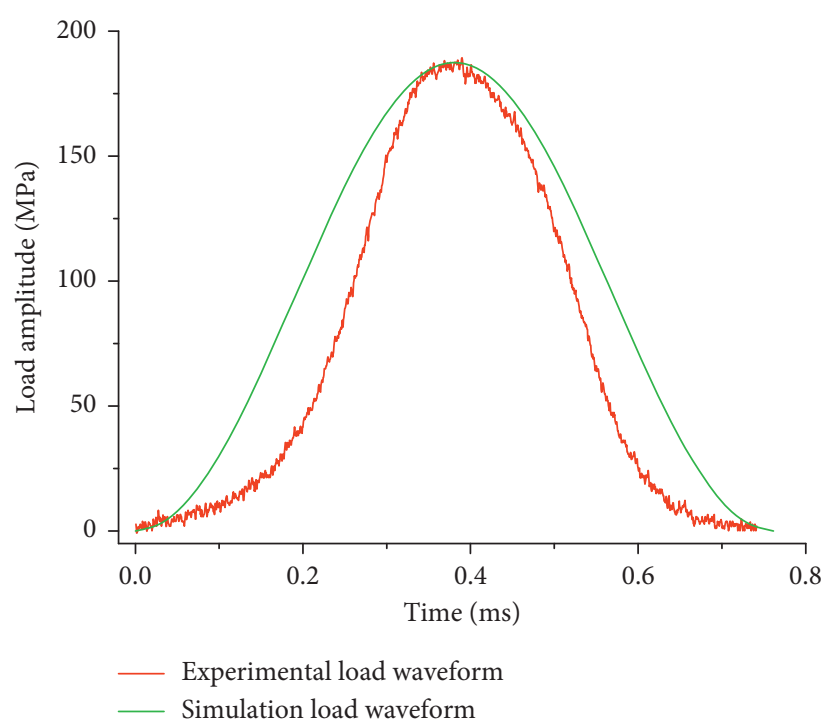

Figure 9: Test and simulation input load curve.

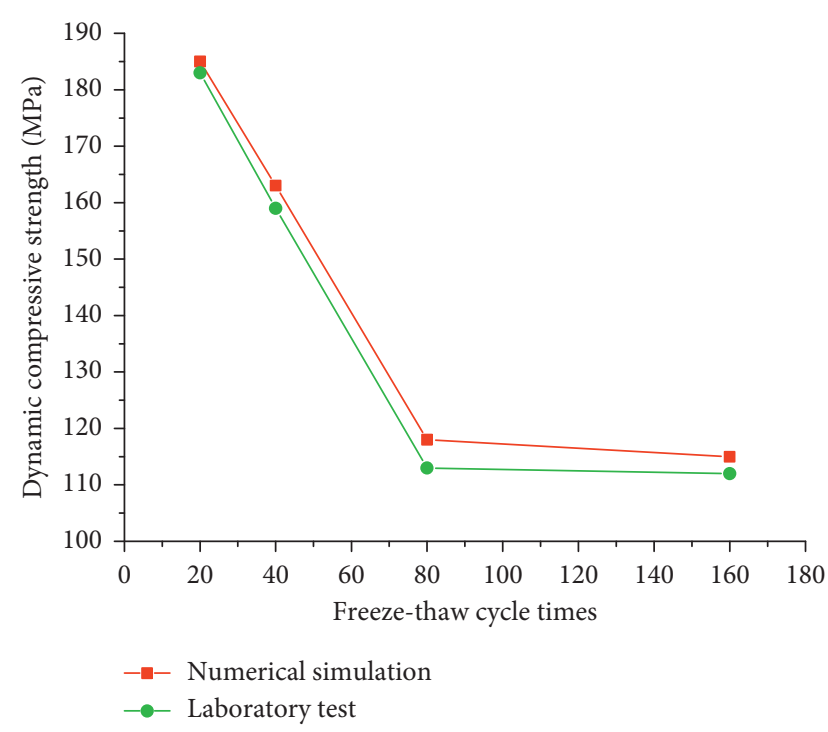

FIGURE 10: Dynamic compressive strength of sandstone specimens under indoor and numerical SHPB tests.

3.3.3. Analysis of Study Results on Degradation of Dynamic Mechanical Parameters of Sandstone with Different FreezeThaw Cycles. The sandstones with 150, 200, 250, and 300 freeze-thaw cycles are simulated under the same impact load, and the stress-strain curve of sandstones is obtained as shown in Figure 12. It is observed that when the number of freeze-thaw cycles increased from 150 to 200 times, the peak stress of the specimen, namely, the maximum compressive strength, decreased greatly. However, when the number of freeze-thaw cycles is greater than 200 times, the amplitude of the peak stress of the stress-strain curve reduced gradually. Combined with the data from the indoor SHPB impact test, it can also be found that as the number of freeze-thaw cycles increases, the compressive strength of the specimen decreases more slowly after reaching a certain number of freeze-thaw cycles. In the laboratory test, there is a long pressure dense section, and the stress-strain curve in the simulation started directly from the elastic section. Therefore, there is a slight difference between the stress-strain curve in the numerical simulation and the test.

Assuming that the ratio of dynamic compressive strength to static compressive strength is dynamic compressive strength growth factor (DIF) [22], the curves of dynamic compressive strength, static compressive strength, and DIF with freeze-thaw cycles of sandstone specimens under the same strain rate are shown in Figure 13. It is observed that the dynamic compressive strength and static compressive strength both decrease with the increase of freeze-thaw cycles, while the value of DIF is always around 4.5 , indicating that there is a certain correlation between dynamic compressive strength and static compressive strength, the correlation fluctuates with the number of freeze-thaw cycles, and DIF as a whole shows a slight downward trend.

The ratio between dynamic elastic modulus and static elastic modulus is defined here as a modulus proportional coefficient. Under the same strain rate, the curves of static elastic modulus, dynamic elastic modulus, and modulus proportional coefficient of sandstone specimens changing with the number of freeze-thaw cycles are shown in Figure 14. It is observed that in the numerical simulation experiment, there is a certain correlation between dynamic elastic modulus and static elastic modulus, which increase with the increase of freeze-thaw cycles. This means that with the increase of freeze-thaw cycles, the degradation of dynamic elastic modulus is gradually affected by the static elastic modulus and the number of freeze-thaw cycles.

3.4. Study on Dynamic Mechanical Parameters of Freeze-Thaw Cycle Sandstone under Different Strain Rates. Numerical simulation research of the freeze-thawed sandstone with different loading strain rates is carried out using LS-DYNA, 


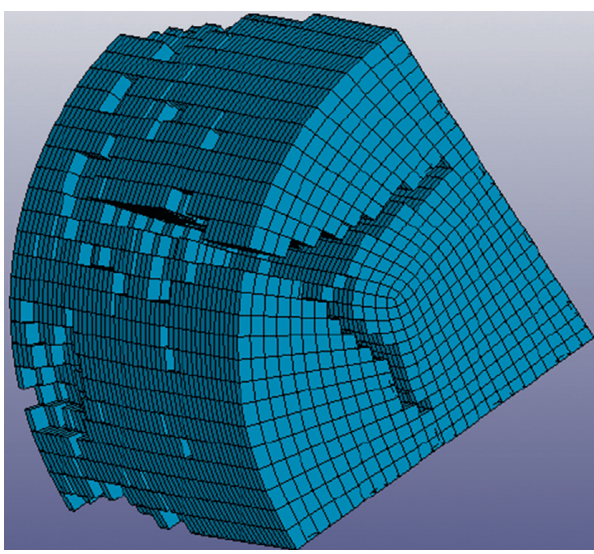

(a)

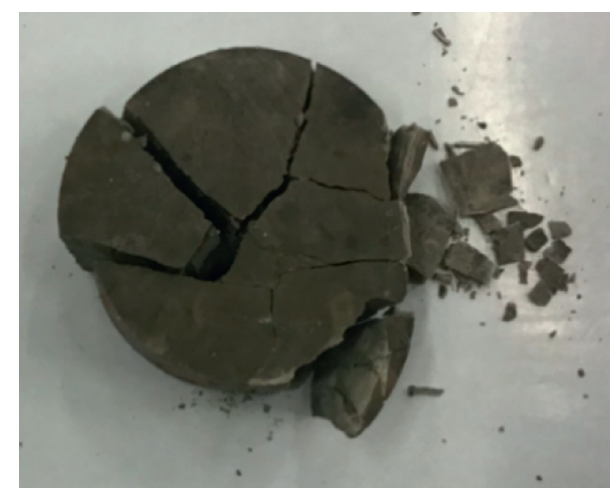

(b)

FIgURE 11: Failure modes of freeze-thaw cycle sandstone at $0.07 \mathrm{MPa}$ impact pressure. (a) Typical failure patterns of a quarter of the specimen under numerical simulation. (b) Typical failure modes of laboratory test specimens.

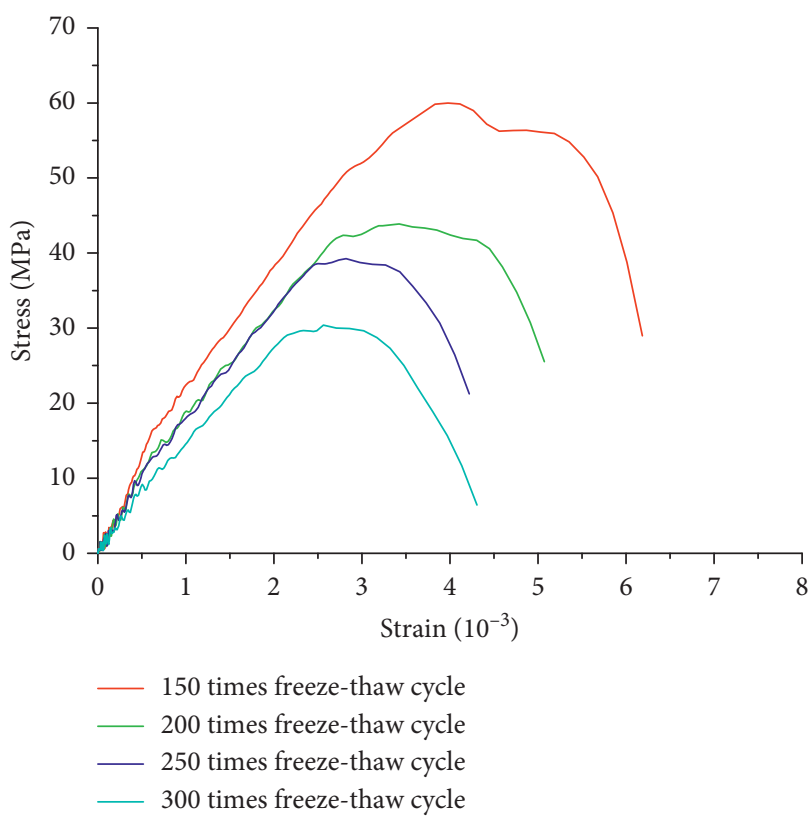

FIGURE 12: Stress-strain curve of different freeze-thaw cycles.

a type of numerical simulation software. The software can overcome the weakness in accurate control of strain rates in the laboratory SHPB experiment. It is observed from Figure 15 that with the increase of strain rate, the compressive strength under $200 \mathrm{~s}^{-1}$ significantly increases in comparison with that in static state. However, when the strain rate increases to $380 \mathrm{~s}^{-1}$ of its original value, its dynamic compressive strength only increases by less than 0.1 times; when the strain rate reaches $580 \mathrm{~s}^{-1}$, the dynamic compressive strength increases by an obviously smaller amount; under the strain rate of $750 \mathrm{~s}^{-1}$, the mean increase of its dynamic compressive strength is only 0.03 times of $580 \mathrm{~s}^{-1}$. It shows that the dynamic compressive strength of sandstones will gradually become stable with the strain rate increasing to a certain extent under the same freeze-thaw cycles.

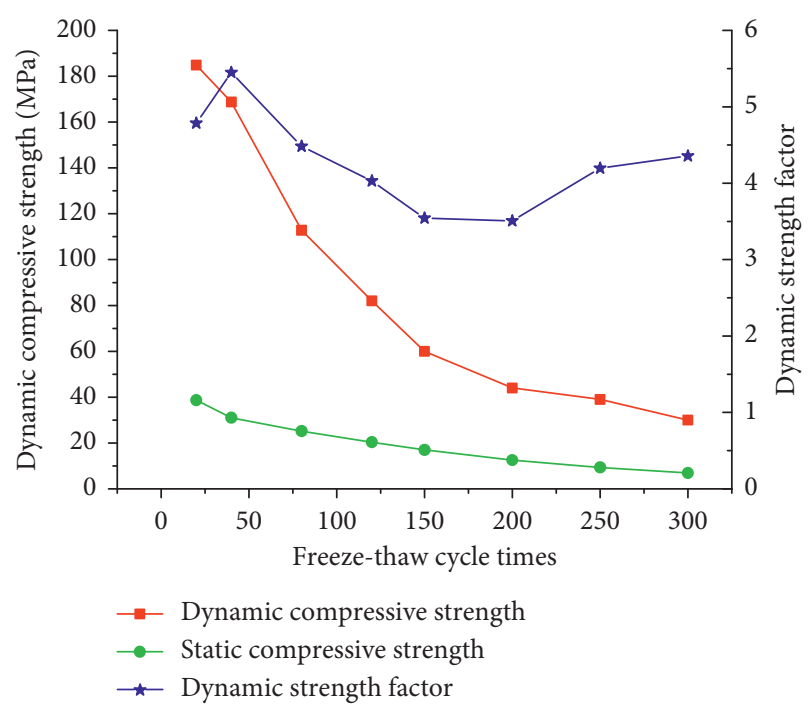

FIGURE 13: Curves of static and dynamic compressive strength and dynamic strength factor of sandstone with the number of freezethaw cycles.

It is observed from Figure 16 that the dynamic elastic modulus of sandstones is affected by both the number of freeze-thaw cycles and the strain rate. Under different strain rates, the law of the dynamic elasticity modulus varying with the number of freeze-thaw cycles is similar. When the strain rate increases to a certain extent, the influence of strain rate on dynamic elasticity modulus is weakened. The law is similar to the dynamic compressive strength.

The least-square method is used to fit the fitting formula of dynamic compressive strength of high-order freeze-thaw cycle rock mass under different strain rates, as shown in Table 4.

Table 4 indicates that the fitting formulas describing the fact that dynamic compressive strength of sandstones varies with freeze-thaw cycles under different strain rates are similar with high correlation coefficient $R$. Therefore, the 


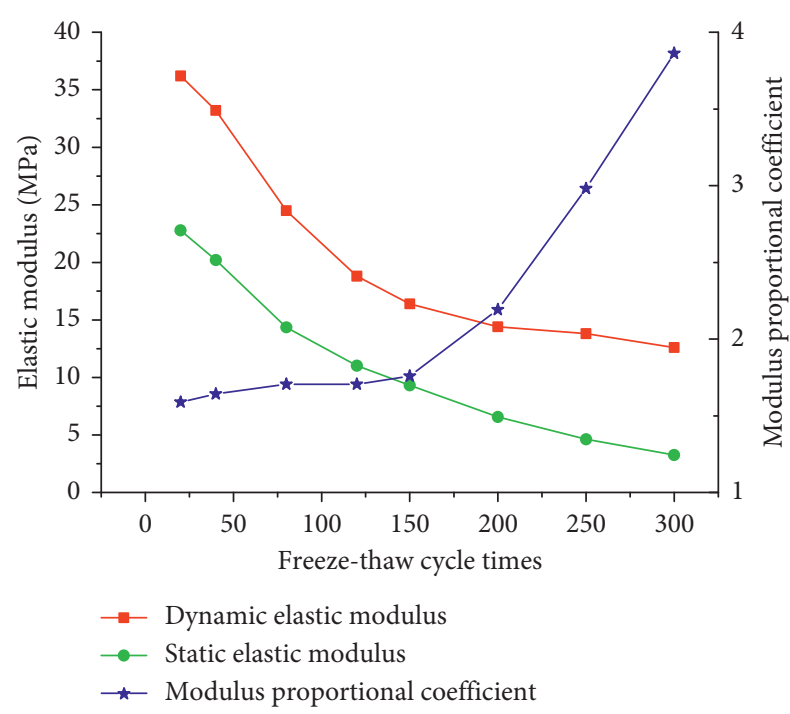

FIgURE 14: Variation rule of dynamic and static elastic modulus and modulus proportional coefficient with freeze-thaw cycles.

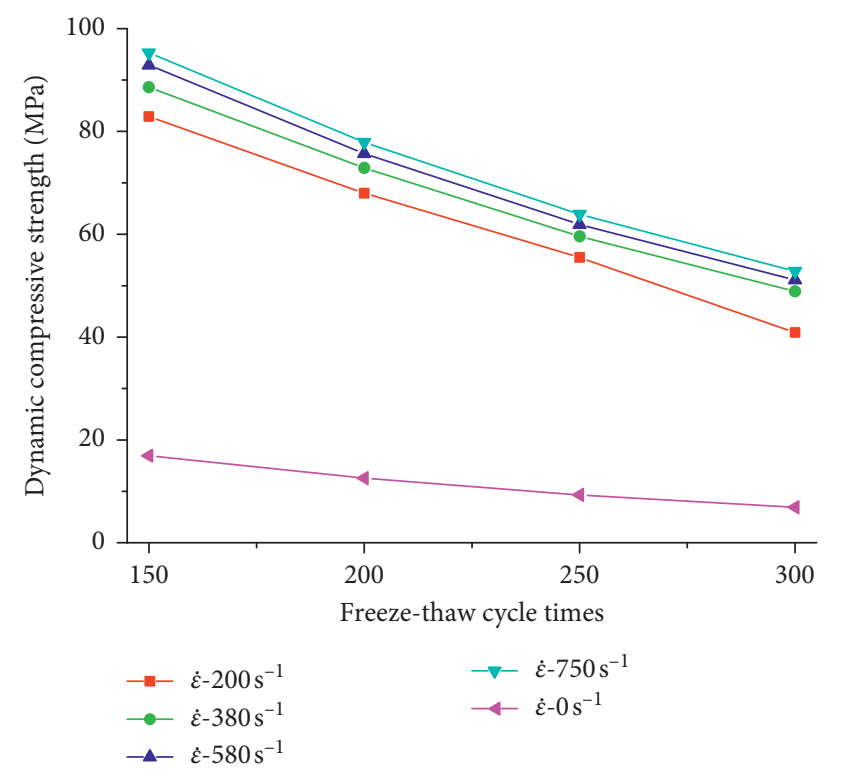

FIGURE 15: Influence of strain rate on dynamic compressive strength of rock mass under different freeze-thaw cycles.

coefficients of the fitting formula in Table 4 are refitted to obtain the fitting equation (4), the fitting formula of dynamic compressive strength of sandstones with freeze-thaw cycles, which is related to the strain rate:

$$
y=M e^{-0.004 x},
$$

where $M=89.5 \dot{\varepsilon}^{0.0988}$ correlation coefficient $R=0.9987$, in which $\dot{\varepsilon}$ referred to strain rate.

This formula can be used to predict the dynamic compressive strength of sandstone under different freezethaw cycles based on the number of freeze-thaw cycles and strain rate, and the dynamic compressive strength of rock

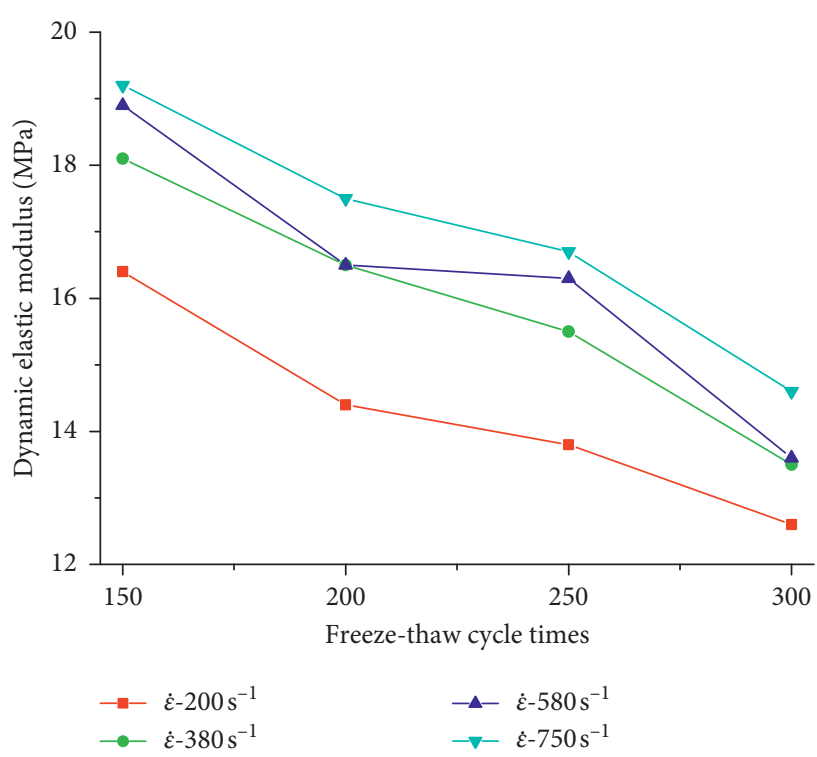

FIgURE 16: Influence of input load on dynamic elastic modulus of rock mass under different freeze-thaw cycles.

TABle 4: Dynamic compressive strength fitting formula of freezethaw cycle sandstone under different strain rates.

\begin{tabular}{lcc}
\hline $\begin{array}{l}\text { Strain rate } \\
\left(\mathrm{s}^{-1}\right)\end{array}$ & $\begin{array}{c}\text { Fitting formula }(x \text { is the number } \\
\text { of freeze-thaw cycles) }\end{array}$ & $\begin{array}{c}\text { Correlation } \\
\text { coefficient } R\end{array}$ \\
\hline 200 & $y=151.0 e^{-0.004 x}$ & 0.978 \\
380 & $y=160.9 e^{-0.004 x}$ & 0.999 \\
580 & $y=168.5 e^{-0.004 x}$ & 0.998 \\
750 & $y=171.6 e^{-0.004 x}$ & 0.997 \\
\hline
\end{tabular}

mass has certain reference value for the safety and stability of practical engineering.

\section{Conclusion}

In this paper, the indoor SHPB impact compression test was carried out using the sandstone under freeze-thaw cycles as the object. Also, the mechanical parameter degradation law of sandstones under numerous freeze-thaw cycles was studied by LS-DYNA, the dynamic finite element. Results are shown as follows:

(1) With the increase of freeze-thaw cycles in sandstones, the dynamic compressive strength and elastic modulus of rock specimens decreased under the impact pressures of $0.04 \mathrm{MPa}, 0.055 \mathrm{MPa}$, and $0.07 \mathrm{MPa}$. Under the same freeze-thaw cycle, the dynamic compressive strength of sandstone under $0.04 \mathrm{MPa}$ air pressure suffered from the highest damage rate after being affected by freeze-thaw cycle, and such strength suffered from the lowest damage rate under $0.07 \mathrm{MPa}$ air pressure, which indicates that the smaller was the strain rate of sandstone, the greater was the influence of the strain rate on the mechanical properties under the freezethaw cycle. 
(2) When the freeze-thaw cycle of sandstone increases in arithmetic progression, the decrease of stress-strain peak curve of sandstone tapered off under the same impact pressure and the dynamic compressive strength growth factor fluctuated around 4.5 along with the freeze-thaw cycles. Also, the static elastic modulus and the freeze-thaw cycles had a gradually increased influence on the degradation of dynamic elasticity modulus.

(3) With the increase of strain rate, the dynamic compressive strength and dynamic elastic modulus of sandstone with different freeze-thaw cycles decreased with the increase of freeze-thaw cycles and gradually approached a stable value, indicating that the deterioration of sandstone was greater with the strain rate changing below $200 \mathrm{~s}^{-1}$.

In this paper, only the influence of freeze-thaw cycle and impact load on the deterioration of sandstone mechanical parameters was studied. How to improve the soil environment was not considered to increase the bearing capacity of the foundation and therefore to improve the safety and service life of railways $[23,24]$. This would be studied in future studies.

\section{Data Availability}

The curve data used to support the findings of this study are available from the corresponding author upon request.

\section{Conflicts of Interest}

The authors declare that they have no conflicts of interest.

\section{Acknowledgments}

This work was supported by the Fundamental Research Funds for the National Natural Science Foundation of China (51779197, 51979208, and 51774222), the Postdoctoral Innovation Research Post of Hubei Province of China (20201jb001), the Hubei Key Laboratory of Roadway Bridge and Structure Engineering (Wuhan University of Technology) (no. DQJJ201904), the Fundamental Research Funds for the Central Universities (WUT: 2019IVA098), and the Youth Talent Project of Science and Technology Research Program of Hubei Provincial Department of Education (Q20192801).

\section{References}

[1] Y. Luo, D. Qu, G. Wang, X. Li, and G. Zhang, "Degradation model of the dynamic mechanical properties and damage failure law of sandstone under freeze-thaw action," Soil Dynamics and Earthquake Engineering, vol. 132, p. 106094, 2020.

[2] J. Eslami, C. Walbert, A.-L. Beaucour, A. Bourges, and A. Noumowe, "Influence of physical and mechanical properties on the durability of limestone subjected to freeze-thaw cycles," Construction and Building Materials, vol. 162, pp. 420-429, 2018.

[3] T. Jiang, J. Zhang, and H. Wu, "Experimental and numerical study on hydraulic fracture propagation in coalbed methane reservoir," Journal of Natural Gas Science and Engineering, vol. 35, pp. 455-467, 2016.

[4] Q. Liu, S. Huang, Y. Kang, and X. Liu, "A prediction model for uniaxial compressive strength of deteriorated rocks due to freeze-thaw," Cold Regions Science and Technology, vol. 120, no. 1, pp. 96-107, 2015.

[5] J. Yu, X. Chen, H. Li, J.-W. Zhou, and Y.-Y. Cai, "Effect of freeze-thaw cycles on mechanical properties and permeability of red sandstone under triaxial compression," Journal of Mountain Science, vol. 12, no. 1, pp. 218-231, 2015.

[6] B. Ke, K. Zhou, C. Xu, H. Deng, J. Li, and F. Bin, "Dynamic mechanical property deterioration model of sandstone caused by freeze-thaw weathering," Rock Mechanics and Rock Engineering, vol. 51, no. 9, pp. 2791-2804, 2018.

[7] X. Deng, D. Yuan, D. Yang, and C. Zhang, "Back analysis of geomechanical parameters of rock masses based on seepagestress coupled analysis," Mathematical Problems in Engineering, vol. 2017, Article ID 3012794, 13 pages, 2017.

[8] X. Xu, Y. Dong, and C. Fan, "Laboratory investigation on energy dissipation and damage characteristics of frozen loess during deformation process," Cold Regions Science and Technology, vol. 109, pp. 1-8, 2015.

[9] Y. Deng, M. Chen, Y. Jin, and D. Zou, “Theoretical analysis and experimental research on the energy dissipation of rock crushing based on fractal theory," Journal of Natural Gas Science and Engineering, vol. 33, pp. 231-239, 2016.

[10] J. Zhang, H. Deng, A. Taheri, B. Ke, and C. Liu, "Deterioration and strain energy development of sandstones under quasistatic and dynamic loading after freeze-thaw cycles," Cold Regions Science and Technology, vol. 160, pp. 252-264, 2019.

[11] M. S. Alam, T. Chakraborty, V. Matsagar, K. S. Rao, P. Sharma, and M. Singh, "Characterization of kota sandstone under different strain rates in uniaxial loading," Geotechnical and Geological Engineering, vol. 33, no. 1, pp. 143-152, 2015.

[12] H. Yavuz, "Effect of freeze-thaw and thermal shock weathering on the physical and mechanical properties of an andesite stone," Bulletin of Engineering Geology and the Environment, vol. 70, no. 2, pp. 187-192, 2011.

[13] Z. Wang, X. Chen, X. Xue, L. Zhang, and W. Zhu, "Mechanical parameter inversion in sandstone diversion tunnel and stability analysis during operation period," Civil Engineering Journal, vol. 5, no. 9, pp. 1917-1928, 2019.

[14] M. Mutlutürk, R. Altindag, and G. Türk, "A decay function model for the integrity loss of rock when subjected to recurrent cycles of freezing-thawing and heating-cooling," International Journal of Rock Mechanics and Mining Sciences, vol. 41, no. 2, pp. 237-244, 2004.

[15] P. Wang, J. Xu, S. Liu, S. Liu, and H. Wang, "A prediction model for the dynamic mechanical degradation of sedimentary rock after a long-term freeze-thaw weathering: considering the strain-rate effect," Cold Regions Science and Technology, vol. 131, pp. 16-23, 2016.

[16] X.-L. Zhang, Y.-Y. Jiao, and J.-F. Ma, "Simulation of rock dynamic failure using discontinuous numerical approach," Computers and Geotechnics, vol. 96, pp. 160-166, 2018.

[17] P.-P. He and Z.-D. Cui, "Dynamic response of a thawing soil around the tunnel under the vibration load of subway," Environmental Earth Sciences, vol. 73, no. 5, pp. 2473-2482, 2015.

[18] C. N. Bai, J. P. Guo, and J. G. Li, "Study on disease analysis and treatment of high slope in Longgong Station of Shuohuang Railway," Journal of Railway Engineering, vol. 34, no. 2, pp. 47-52, 2017. 
[19] W. Dong, X.-D. Shen, H.-J. Xue, J. He, and Y. Liu, "Research on the freeze-thaw cyclic test and damage model of Aeolian sand lightweight aggregate concrete," Construction and Building Materials, vol. 123, pp. 792-799, 2016.

[20] X. Luo, N. Jiang, C. Zuo, Z. Dai, and S. Yan, "Damage characteristics of altered and unaltered diabases subjected to extremely cold freeze-thaw cycles," Rock Mechanics and Rock Engineering, vol. 47, no. 6, pp. 1997-2004, 2014.

[21] R. Song, L. Zheng, Y. Wang, and J. Liu, "Effects of pore structure on sandstone mechanical properties based on micro-CT reconstruction model," Advances in Civil Engineering, vol. 2020, Article ID 9085045, 21 pages, 2020.

[22] Q. Ma, D. Ma, and Z. Yao, "Influence of freeze-thaw cycles on dynamic compressive strength and energy distribution of soft rock specimen," Cold Regions Science and Technology, vol. 153, pp. 10-17, 2018.

[23] M. Yao, Q. Wang, B. Ma, Y. Liu, Q. Yu, and Y. Han, "Effect of freeze-thaw cycle on shear strength of lime-solidified dispersion soils," Civil Engineering Journal, vol. 6, no. 1, pp. 114-129, 2020.

[24] A. E. Abu El-Maaty, "Enhancing of CBR strength and freezethaw performance of silty subgrade using three reinforcement categories," Civil Engineering Journal, vol. 2, no. 3, pp. 73-85, 2016. 